\title{
Los pobres y la praxis de lucha popular como lugar epistémico-político
}

\author{
Os pobres e a práxis da luta popular como lugar \\ epistêmico-político
}

\section{The poor and the praxis of popular struggle as an epistemic-political place}

\author{
iD (9) Félix Pablo Friggeri \\ Universidad Federal de la Integración Latinoamericana (UNILA), Foz do Iguaçu, Paraná, \\ Brasil \\ fpfriggeri@hotmail.com
}

\begin{abstract}
Resumen: Presento, en este trabajo, desde una valoración del potencial político y epistémico de los aportes del Cristianismo de Liberación y de la Teología y Filosofía de la Liberación, una mirada sobre algunos de sus conceptos claves cuyo análisis puede servir actualmente en nuestra región latinoamericana para el diálogo entre los movimientos populares y para el debate de las Ciencias Sociales que se comprometen con ellos. Estos conceptos son los de pobre, pueblo y praxis y sabiduría popular. También planteo tres diálogos dentro de la gran multiplicidad de posibilidades: con el Socialismo Indoamericano de Mariátegui; con el Peronismo Revolucionario; y con las propuestas del Papa Francisco. Concluyo destacando algunos de los temas claves para estos diálogos contenidos en la profunda actualidad de estos planteos de liberación.
\end{abstract}

Palabras clave: Pobre. Pueblo. Cristianismo de Liberación. Praxis popular. Teología de la Liberación.

Resumo: Apresento, neste trabalho, a partir de uma avaliação do potencial político e epistêmico das contribuições do Cristianismo da Libertação e da Teologia e Filosofia da Libertação, um olhar sobre alguns 
de seus principais conceitos, cuja análise pode servir atualmente, em nossa região latino-americana, para o diálogo entre os movimentos populares e o debate das Ciências Sociais, áreas que com eles se comprometem. Esses conceitos são os de pobre, povo e práxis e sabedoria popular. Também proponho três diálogos dentro da grande multiplicidade de possibilidades: com o socialismo indo-americano de Mariátegui; com o peronismo revolucionário; e com as propostas do Papa Francisco. Concluo destacando algumas das principais questões para esses diálogos contidos na profunda relevância dessas questões de libertação.

Palavras-chave: Pobre. Povo. Cristianismo de Libertação. Práxis Popular. Teologia da Libertação.

Abstract: Based on an assessment of the political and epistemic potential of the contributions of Christianity of Liberation and of Theology and Philosophy of Liberation, in this paper I look at some of its key concepts that can currently be used in Latin American for the dialogue among the popular movements and for the debate of the Social Sciences that commit themselves to them. These concepts are those of Poor, People and Praxis and Popular Wisdom. I also propose three dialogues within the great multiplicity of possibilities: with the Mariátegui Indo-American Socialism; with Revolutionary Peronism; and with the proposals of Pope Francis. I conclude by highlighting some of the key issues for these dialogues contained in the profound relevance of these issues of liberation.

Keywords: Poor. People. Liberation Christianity. Popular praxis. Liberation Theology.

Data de recebimento: 30/06/2019

Data de aceite: 03/10/2019 
Los pobres y la praxis de lucha popular como lugar epistémico-político Félix Pablo Friggeri

\section{Introducción}

Propongo, en este trabajo, desde una valoración del potencial político y epistémico que tienen tanto el Cristianismo de Liberación como la Teología y Filosofía de Liberación en América Latina, algunos elementos claves de estas corrientes que pueden contribuir a enriquecer el diálogo actual entre los distintos movimientos latinoamericanos comprometidos con las mayorías populares y los debates de las Ciencias Sociales que los acompañan.

No pretendo, aquí, hacer un desarrollo exhaustivo del contenido de los conceptos que se trabajan, ni de las diferencias y debates en torno a los mismos. Pretendo, sí, presentarlos intentando destacar su potencialidad en las dos dimensiones apuntadas: el potencial político para nuestra actualidad en relación a las distintas vertientes comprometidas actualmente con lo populary el potencial epistémico para un diálogo entre las distintas corrientes de pensamiento que las alimentan.

Realizo este ejercicio convencido que tanto la Teología como la Filosofía de la Liberación tienen un potencial de plena actualidad para seguir enriqueciendo la praxis y la reflexión que acompaña el accionar los movimientos populares contemporáneos latinoamericanos, así como el Cristianismo de Liberación sigue siendo un aporte clave para la militancia que los anima.

Unido a esto está la riqueza que estos conceptos teológicos y filosóficos tienen para el diálogo con los debates actuales en las Ciencias Sociales comprometidas con una transformación a favor de las mayorías populares en nuestra región. Entiendo que, aún existiendo conexiones muy valiosas, queda un inmenso campo por trabajar en esta relación del trabajo de la Teología y la Filosofía de la Liberación con las Ciencias Sociales, y que sigue siendo un desafío profundizarse en esa tarea.

En el primer punto trabajo la presencia del concepto de pobre desde elementos ofrecidos tanto desde la Teología como desde la 
Los pobres y la praxis de lucha popular como lugar epistémico-político Félix Pablo Friggeri

Filosofía de la Liberación. Trabajando las dos dimensiones, política y epistémica, profundizo un poco más en esta última. Comienzo ligando el concepto al planteo pastoral y hermenéutico de opción por los pobres. Destaco especialmente al pobre como "lugar teológico" y su ampliación como "lugar epistémico". Por la riqueza que entiendo tiene, destaco la potencialidad del concepto de exterioridad -que trabajó especialmente Enrique Dussel- también principalmente desde el ámbito epistémico. Me refiero, finalmente, al carácter dialéctico de la pobreza, lo cual ubica el tema dentro de un análisis estructural.

En el segundo punto, trabajo otro concepto íntimamente relacionado con el anterior y que ha sido tratado también tanto por la Teología como por la Filosofía de la Liberación: el concepto de pueblo. Recuerdo, primero, la importancia que toma la noción de pueblo de Dios tanto en la Teología de la Liberación como en documentos eclesiales. También el carácter de sujeto epistémico que le otorga al pueblo la primer Filosofía de la Liberación. Paso, enseguida, a presentar brevemente el tema de la abarcatividad de este concepto y de su relación con los de nación y de clase y los distintos acentos -ya sea en la unidad o en el conflicto- presentes en su discusión. Luego, paso a destacar una serie de elementos que forman parte de las notas distintivas del tratamiento del concepto en los ámbitos de la Teología y la Filosofía de la Liberación: la necesidad de comprender lo humano desde lo popular; la igualdad fundamental de sus miembros; el carácter comunitario y organizacional; el sentido solidario como constitutivo y su presencia preponderante en los pobres; su relación con el concepto de exterioridad tratado más arriba; desde allí, su capacidad para ser proveedor de los valores fundamentales para la praxis de lucha por la liberación; su carácter de símbolo centrado en el arraigo; su relacionamiento con el concepto de pobre desde lo cultural; su identificación con los más humildes; $y$, finalmente, el concepto de pueblo crucificado -de Ignacio Ellacuría-y su importancia clave para esta reflexión tanto desde lo político como desde lo epistémico. Propongo, seguidamente, la consideración de los pobres como 
Los pobres y la praxis de lucha popular como lugar epistémico-político Félix Pablo Friggeri

corazón del pueblo. Finalmente planteo el tema de la necesidad de diálogo entre las dos dicotomías claves para el análisis del concepto: la clasista y la "populista", que plantea la contraposición oligarquía/pueblo y, relacionando con ésta última, la idea de "antipueblo".

En el tercer punto trabajo el concepto de praxis, entendida sobre todo como praxis de liberación. Destaco, primero, su lugar fundamental tanto en la Teología como en la Filosofía de la Liberación y presento una definición relacionada al concepto de exterioridad. Luego, planteo el papel que tiene el Cristianismo de Liberación en esta praxis y su relación con los otros movimientos populares. Analizo el por qué se considera teológica a la praxis de liberación y su abarcatividad, tanto de hechos más notables como de la lucha cotidiana. La presencia de la reflexión en esta praxis es el otro elemento central y allí la necesidad de una actitud de "discipulado", principalmente del intelectual y de los "dirigentes" frente al pueblo. Esto lleva a una valorización de lo experiencialsapiencial, de la sabiduría popular como espacio clave de esta reflexión y al papel del Cristianismo de Liberación en su relación con las elaboraciones teológicas principalmente.

En el cuarto punto planteo tres diálogos posibles dentro de la multiplicidad de movimientos y espacios con los cuales es necesario establecer y consolidar relaciones prácticas y teóricas. El primero es con la propuesta de José Carlos Mariátegui que tiene la virtud de tratar de articular una reflexión sobre la praxis ancestral indígena con un proyecto socialista propio y original, lo que el autor Ilamó "Socialismo Indoamericano". El segundo diálogo es con el peronismo, sobre todo en su vertiente revolucionaria. Esta elección la justifico por la importancia paradigmática que tiene este movimiento entre las propuestas llamadas como "nacionalpopulares" o "populistas" (en un sentido positivo, en la línea de Ernesto Laclau). También es importante por su clara presencia inspiradora tanto para la Filosofía como para la Teología en especial en su desarrollo en Argentina, lo cual se reactualiza y toma una dimensión universalmente amplia desde la relación que puede 
Los pobres y la praxis de lucha popular como lugar epistémico-político Félix Pablo Friggeri

establecerse con muchas de las ideas que viene proponiendo el Papa Francisco. El tercer diálogo es, justamente, con el planteo del actual Papa argentino. Se justifica por la repercusión que tiene en la reflexión teológica latinoamericana las propuestas que viene realizando y que, por varios elementos que se exponen, posibilitan un renovado diálogo con la doctrina oficial de la Iglesia Católica, diálogo que se había complicado severamente en los anteriores papados.

Concluyo recapitulando los temas fundamentales que, estando presentes en la vida del Cristianismo de Liberación y en las elaboraciones de la Teología y la Filosofía de la Liberación, pueden ser importantes para un diálogo con los movimientos populares de nuestra región y para los debates de las Ciencias Sociales que se referencian en ellos.

\section{El valor epistémico-político del concepto teológico- filosófico de pobre}

La Teología de la Liberación -y también la Filosofía de la Liberación- supieron replantear la problemática de los pobres dándole una centralidad y una valoración clave para la interpretación tanto del contenido bíblico y la acción eclesial como de la realidad latinoamericana. Entiendo que puede afirmarse que la reflexión más rica sobre este concepto, por lo menos a nivel regional y posiblemente a escala universal también, proviene de los trabajos de estos dos planteos interrelacionados.

El movimiento que origina la Teología de la Liberación tiene también expresiones en manifestaciones oficiales de la Iglesia Católica y la más emblemática es la que surge de la II Conferencia General del Episcopado Latinoamericano en Medellín, Colombia. Allí va a consagrarse el concepto de "opción por los pobres", que marcará la vida de la Iglesia latinoamericana en gran parte por su adhesión, pero también por su rechazo. Surgirá no solo "como una 
Los pobres y la praxis de lucha popular como lugar epistémico-político Félix Pablo Friggeri

prioridad pastoral, sino como una hermenéutica de la Palabra de Dios y de la realidad", por esto planteó un "lugar teológico", un lugar epistémico desde América Latina que desafía duraderamente la praxis eclesial (VERDUGO, 2018, p. 120).

Este tema del lugar epistémico es planteado también en los albores de la Filosofía de la Liberación. Se habla de la necesidad de un "pensar sub-versivo" para lo cual es clave el "desde": "[...] un pensar sub-versivo es el que asume la riesgosa tarea de reflexionar 'desde abajo', desde el polo del oprimido y de la periferia, exoyectando las categorías de la dominación y develando sus contradicciones estructurales" (ARDILES, 1973, p. 25).

Este lugar "desde", desde abajo, desde el subsuelo social, exige también "replantear el problema del pensamiento desde el subsuelo mismo de nuestra sociedad" (KUSCH, 1978, p. 73).

Por su parte, la Teología de la Liberación realiza dos aportes fundamentales desde su utilización del concepto de pobre. El primero es proponerlo como concepto dinámico que reconoce el protagonismo político de los pobres (LOWY, 2016, p. 76). El segundo es hacer de los pobres una fuente epistémica para la construcción del conocimiento. En ambos aportes es clave otro concepto: el de praxis, que analizamos más abajo.

Además, esta opción conecta en forma subordinada a la Teología de la Liberación con lo que sería denominado Cristianismo de Liberación: con la vida de compromiso de las comunidades cristianas con las luchas populares. Acertadamente, entiendo, Löwy (2016, p. 74) habla de "Cristianismo de la Liberación", que como movimiento es anterior y mucho más amplio de lo que se comprende muchas veces tanto como "Teología" como de "Iglesia". La Teología es solo un aspecto o momento del Cristianismo de Liberación (AQUINO JÚNIOR, 2016, p. 249).

Esta forma de vivir el cristianismo si bien atiende a lo que podríamos llamar las "pobrezas" del pobre-desde donde parten las denuncias de la pobreza y la opresión como pecados estructurales y el compromiso con una praxis de liberación- termina destacando 
Los pobres y la praxis de lucha popular como lugar epistémico-político Félix Pablo Friggeri

fundamentalmente las "riquezas" del pobre, es decir, su potencial epistémico-político liberador (BOFF, 1984, p. 25).

Unido a esto, la Teología de la Liberación afirma el "carácter político" de los pobres. Es que si se observa la realidad de "los desposeídos y empobrecidos de América Latina" puede verse que "su pobreza consciente y activamente asumida representa antes y después de la revolución una fuerza fundamental de cambio social y un referente imprescindible para la reestructuración de la sociedad" (ELLACURÍA, 1981, p. 227).

El concepto de pobre que maneja la Teología de la Liberación tiene dos grandes fuentes. Una es la Biblia, la otra es su utilización popular en América Latina. Esta segunda fuente no siempre ha sido recordada debidamente. En su utilización, este concepto aparece como más amplio que el de clase obrera (LÖWY, 2016, p. 131), aunque sí relacionado a la problemática de clase, porque también se sostiene que "el pobre del que se habla en esta opción preferencial son las clases populares oprimidas" (BOFF, 1986, p. 37). Y la gran pregunta que surge en la relación con las Ciencias Sociales es si este concepto de pobre puede aportar a una ampliación del de proletariado en América Latina.

Entiendo que conviene destacar un aporte que viene de la Filosofía de la Liberación y, especialmente, de su referente más importante, que es Enrique Dussel. Es su planteo de la "exterioridad" del pueblo y del pobre frente al sistema capitalista que explicita la potencialidad política y epistémica de estos conceptos.

Dussel habla de una "positiva exterioridad cultural" que capacita al pueblo, al pobre, para cuestionar el orden capitalista colonial y para suscitar alternativas originales y auténticamente superadoras de ese orden. Esto tanto en lo político como en lo epistémico. La positividad es clave también para entender la valoración del concepto de pobre. Cuando Dussel (1996, p. 83) habla del "ethos de la liberación" sostiene que "es el amor al otro como otro, como exterioridad; amor al oprimido, pero no en su situación de oprimido, sino como sujeto de la exterioridad". 
Los pobres y la praxis de lucha popular como lugar epistémico-político Félix Pablo Friggeri

Esta exterioridad es definitoria del pensamiento que surge de la periferia (DUSSEL, 1996, p. 26).

Esta positividad cultural de la exterioridad tiene la virtualidad de capacitar para crear alternativas al sistema dominante: "Las clases oprimidas o populares de las naciones dependientes son las que guardan en su cultura propia la máxima exterioridad del sistema actual mundial; ellas pueden presentar una alternativa real y nueva a la humanidad futura, dada su metafísica alteridad" (DUSSEL, 1996, p. 92).

El autor establece un vínculo fundamental entre este concepto y el de liberación. Lo primero es que él entiende que la exterioridad es "la categoría más importante [...] de la filosofía de la liberación" (DUSSEL, 1996, p. 55). Para él (1996, p. 15), "la exterioridad total" es "el futuro de liberación", por eso el pueblo "como exterioridad es reserva escatológica" (DUSSEL, 1986, p. 95).

Es un aporte, también, para repensar la ampliación del concepto de proletariado, pensado inicialmente como contestación "desde dentro" del sistema capitalista (DUSSEL, 1996, p. 55).

Esta exterioridad -que Dussel destaca prioritariamente como cultural- tiene una profunda dimensión epistémica: “el pobre descubierto como exterioridad es el comienzo de todo el proceso reflexivo" (DUSSEL, 1973a, p. 182). Así como en la teología, basada en el mensaje bíblico, "sólo los pobres son capaces de sacar de ese mensaje su plenitud" (ELLACURÍA, 1990a, p. 143), la llamada "excelencia académica" en las Ciencias Sociales, es importante pensarla desde lo popular y por ello ser consciente de que su búsqueda profunda y auténtica solo se da en la relación profunda y en la escucha de las mayorías pobres.

También hay que recordar que "la opción por los pobres comienza [...] para Dussel, en la región latinoamericana, desde la problemática del indio" (MORA RODRÍGUEZ., 2007, p. 6). La positiva exterioridad cultural tiene una manifestación fuertemente privilegiada y originaria en lo indígena. Esto lo convierte en una fuente epistémica de riqueza clave: es el pensamiento indígena 
Los pobres y la praxis de lucha popular como lugar epistémico-político Félix Pablo Friggeri

el que "nos abre la comprensión de los problemas americanos" (KUSCH, 1977, p. 13). La propuesta del Movimiento Indígena que podría identificarse como del buen vivir es una expresión de este potencial.

Otro elemento a destacar es el "carácter dialéctico" de la pobreza que subraya Ignacio Ellacuría (1981, p. 226): "Está, ante todo, el carácter dialéctico de los pobres y de la pobreza. En nuestra situación concreta hay pobres 'porque' hay ricos; hay una mayoría de pobres porque hay una minoría de ricos". Esto es reafirmado por otro de los mártires salvadoreños: "Los pobres son, antes que nada, empobrecidos por causa del acaparamiento y explotación de los ricos; y los ricos son enriquecidos a costa del empobrecimiento y miseria de las grandes masas" (MORENO, 1990, p. 164).

\section{Pueblo}

En correlación con la revalorización del concepto de pobre especialmente en la Teología de la Liberación, pero también en la Filosofía de la Liberación, fue dándose una revalorización del concepto de pueblo, íntimamente ligado a aquel. Revalorización igualmente política y epistémica.

En la teología se dio especialmente desde la fuerza que tomó el concepto bíblico de pueblo de Dios, el cual tuvo relevancia en los documentos del Concilio Vaticano II, seguido por los documentos episcopales en América Latina. La Teología de la Liberación asumió fuertemente la primacía interpretativa del mismo en la estructura conceptual básica desde la que construyó sus planteos.

El concepto de pueblo fue trabajado notablemente en la Filosofía dela Liberación, especialmente desde los planteos iniciales realizados en Argentina, destacándose por su influencia las elaboraciones de Enrique Dussel y Rodolfo Kusch. Se afirmaba el carácter de sujeto epistémico del pueblo para la filosofía latinoamericana: 
Los pobres y la praxis de lucha popular como lugar epistémico-político Félix Pablo Friggeri

Frente al planteo liberal-burgués (= moderno) del "sujeto", el "individuo", el "hombre" en abstracto, como puntos de partida del filosofar, una filosofía latinoamericanamente situada comprenderá al Pueblo como sujeto histórico del filosofar. [...] La "Comunidad" organizada como Pueblo es el reducto primero y último del filosofar. (CASALLA, 1973, p. 46).

En conexión con estos planteos, y especialmente en Argentina bajo la indudable influencia del fenómeno peronista, se desarrolló también la llamada Teología del Pueblo. Considerada como una corriente dentro de la Teología de la Liberación, que tiene como pioneros y referentes a las figuras de Lucio Gera y Rafael Tello, especialmente (GALLI, 2018, p. 93-94; SCANNONE, 2016, p. 587).

Elemento clave del análisis, la utilización y el debate del concepto de pueblo es la abarcatividad que se le da. Dentro de esta problemática, tanto en la Teología de la Liberación como en la Filosofía las discusiones oscilaron entre acentuar la unidad o acentuar el conflicto, aunque sin negar ninguno de los dos aspectos.

Por un lado, Juan Carlos Scannone, que resaltó la unidad, sostiene que el uso que se privilegió en la Teología del Pueblo en Argentina -principalmente desde la Comisión Episcopal de Pastoral (Coepal)- designa al "pueblo-nación", como "unidad plural de una cultura común, enraizada en una común historia, y proyectada hacia un bien común compartido" (SCANNONE, 2016, p. 589).

Desde una posición distinta se toma cuidado en sostener una identificación entre pueblo y nación, si este último concepto remarca un sentido de totalidad: "no es aquí un concepto tan amplio que comprenda indistintamente a toda la nación" (PIXLEY; BOFF, 1986, p. 237). Esto vale especialmente para el tipo de nación que se analiza en nuestra región: "La nación periférica como totalidad no es pueblo, sino que lo es por sus clases oprimidas, por aquellas que a veces ni son parte de la nación" (DUSSEL, 1996, p. 91).

Desde la óptica que resalta el conflicto hay una tendencia mayor a dialogar con el concepto de clase, aunque sin confundirse con él. Enrique Dussel (1986, p. 94-95) sostiene que "la clase no es el 
Los pobres y la praxis de lucha popular como lugar epistémico-político Félix Pablo Friggeri

pueblo" y que "pueblo es un concepto más concreto, sintético, que el concepto de clase, que es más abstracto, analítico". Además, en "sentido estricto" el concepto es pensado como "[...] los oprimidos de una nación, y en este caso las clases opresoras no son pueblo [...] es así el 'bloque comunitario' de los oprimidos [...]", en una definición con reminiscencias gramscianas.

En las notas distintivas del concepto de Pueblo que se utiliza hay una serie de elementos que conviene destacar.

Primero, que la comprensión de lo humano debe hacerse desde lo popular: "[...] la vida de cada uno está configurada por lo que es la vida del pueblo en el que se vive, hace connatural la vivencia de que en esta dimensión de colectividad se juega primariamente tanto la salvación como la perdición" (ELLACURÍA, 1990b, p. 202).

Especialmente desde la Teología, también se resalta la igualdad fundamental al interior del pueblo de Dios, particulamente retomando esta noción desde su utilización conciliar (GUTIÉRREZ, 2013, p. 19).

Un tercer elemento es el carácter comunitario y la organización en relación al concepto de pueblo:

[...] ¿qué significa en profundidad, esto de la "comunidad organizada como Pueblo"? O, lo que es lo mismo, ¿la organización popular de una comunidad? [...] de su visualización depende la correcta interpretación de eso que hemos denominado en cambio el "sujeto del filosofar".

[...] cuando una comunidad produce un agrupamiento sobre bases multitudinarias que recogen una ancestral memoria común y el anhelo de un destino también común, nos hallamos en presencia de un Pueblo. Este no es esencialmente otra cosa que una memoria y un destino común, elementos que organizados comunitariamente, dan forma a una Nación y al desarrollo de una Cultura (CASALLA, 1973, p. 47). 
Los pobres y la praxis de lucha popular como lugar epistémico-político Félix Pablo Friggeri

Se plantea también un sentido solidario constitutivo del concepto y particularmente presente entre los más pobres: "el pueblo es el que posee en plenitud la conmiseración por sus iguales" (DUSSEL, 1996, p. 83).

La exterioridad, que, como se expuso más arriba, se relaciona al concepto de pobre, está referenciada también al de pueblo: “El pueblo es exterior y anterior al capitalismo, p. e., en cuanto masas empobrecidas por la disolución de sus modos de apropiación antiguos es exterior en el presente por una economía 'sumergida' y oculta de subsistencia -de lo contrario hace tiempo que hubiera muerto de hambre-" (DUSSEL, 1996, p. 90).

Por esto, es el pueblo el que provee los valores fundamentales para la tarea de lucha por la liberación. La autenticidad y plenitud de la liberación exige "partir de los propios valores de ese pueblo" (GUTIÉRREZ, 1985, p. 132).

Es importante recordar también el planteo del pueblo como símbolo, basado en el concepto de "arraigo":

[...] también y ante todo es un símbolo. Como tal encierra el concepto de lo masivo, lo segregado, lo arraigado, y además lo opuesto a uno, en virtud de connotaciones específicas de tipo cultural. Pero si es símbolo, uno participa de él, y lo hace desde lo profundo de uno mismo, desde lo que no se quiere ser. [...] Por otro lado, aunque no queramos, todos somos pueblo, y en tanto lo segregamos, excluimos esta mancha popular consistente en el arraigo que resquebraja nuestra pretenciosa universalidad, la segregación en la que no querríamos incurrir, o también lo masivo que subordinaría el ego. [...] pueblo, por una parte, es un ente que nos informa en el campo, pero, por otra parte, mueve en nosotros el requerimiento ambiguo de una verdad que nos cuesta asumir. (KUSCH, 1978, p. 8).

Hay, por un lado, un relacionamiento entre los conceptos de pobre y pueblo que acentúa lo cultural. En cercanía, relativa por lo 
Los pobres y la praxis de lucha popular como lugar epistémico-político Félix Pablo Friggeri

menos, con la idea de positividad cultural dusseliana se sostiene que:

En América Latina (AL), son los pobres, quienes, al menos de hecho, conservan como estructurante de su vida y convivencia la cultura propia de su pueblo (Documento de Puebla 414), así como su memoria histórica, y cuyos intereses coinciden con un proyecto histórico común de justicia y paz, siendo así que viven oprimidos por una situación de injusticia estructural y de violencia institucionalizada. Por ello, en AL, al menos de facto, coincide la opción por los pobres y por la cultura. (SCANNONE, 2016, p. 590).

En un texto de análisis histórico-político, se afirma la identificación del pueblo con los más humildes: “[...] 'el pueblo', 'el subsuelo de la patria' como le llamaría Scalabrini Ortiz, es decir, la capa más humilde de la sociedad [...]" (DRI, 1971, p. 20).

Una última reflexión sobre el pueblo que queremos destacar es el aporte que hace Ellacuría (1989, p. 318) al hablar de "pueblo crucificado", al que define como:

[...] aquella colectividad que, siendo la mayoría de la humanidad, debe su situación de crucifixión a un ordenamiento social promovido y sostenido por una minoría que ejerce su dominio en función de un conjunto de factores, los cuales, como tal conjunto y dada su concreta efectividad histórica, deben estimarse como pecado.

Este pueblo crucificado tiene ese doble carácter de víctima y de protagonista de la salvación y de juez del camino a la misma (ELLACURÍA, 1989, p. 332), pero también es el signo de los tiempos "principal, a cuya luz deben discernirse e interpretarse todos los demás" (ELLACURÍA, 1990c, p. 4). 
Los pobres y la praxis de lucha popular como lugar epistémico-político Félix Pablo Friggeri

La consideración del lugar epistémico es clave también para evitar cualquier pretensión de una "lectura neutra":

Los que pretenden que es posible una lectura neutra de un texto de la Escritura cometen un doble error: un error epistemológico, al creer posible una lectura no condicionada; y un error teológico, por cuanto desdeñan el lugar más apto de lectura, que será siempre el destinatario principal al que va dirigido el texto [...] aquí trabajamos con la hipótesis de que en nuestro momento es el pueblo crucificado [...]. (ELLACURÍA, 1990b, p. 205).

La importancia del pueblo crucificado como lugar epistémico está relacionada a su carácter de "Juez". Ellacuría analiza esto relacionando la teología del Siervo de Yahvé con el texto de Mateo 25,36-41 sobre el Juicio:

Es el juicio del reino, el juicio universal y definitivo, que saca a la luz la verdad de Dios entre los hombres; esta verdad está en la identificación del Hijo del hombre, constituido en rey, con los hambrientos, con los sedientos, con los peregrinos, con los desnudos, con los enfermos y los presos. Hijo del hombre es el que sufre con los pequeños; y es este Hijo del hombre, en tanto que encarnado en el pueblo crucificado, el que se va a constituir en juez: el pueblo crucificado es ya juez, aunque no formula juicio teológico, en su propia existencia; y ese juicio es salvación, en cuanto descubra, por oposición, el pecado del mundo y en cuanto posibilita el rehacer lo que está mal hecho; en cuanto propone una exigencia nueva como camino ineludible para conseguir la salvación. Se trata, no lo olvidemos, de un juicio universal en el cual se da sentencia sobre todo el curso de la historia. (ELLACURÍA, 1989, p. 332).

El concepto de Ellacuría cumple un papel fundamental como puente entre pueblo y pueblo de Dios, porque da "carne histórica al pueblo de Dios, evitando así la deshistorización de este concepto fundamental: evitando su falsa espiritualización e ideologización" (ELLACURÍA, 1989, p. 305-306). 
Los pobres y la praxis de lucha popular como lugar epistémico-político Félix Pablo Friggeri

El gran desafío es la articulación de este concepto de pueblo crucificado con el de la praxis histórica de liberación. Esta articulación viene sobre todo por el concepto de "lugar teológico", que es, a la vez, espacio de praxis y de construcción de conocimiento. Por eso es tan importante la doble dimensión política y epistémica fuertemente articuladas, como se destacó desde el principio de este texto. Quizás una de las claves del carácter práxico del Pueblo Crucificado está aquí: "No sabemos si los pobres y las víctimas son santos intercesores para mover a Dios, pero tienen fuerza para mover el corazón. No hacen milagros que violan las leyes de la naturaleza, pero sí hacen milagros que violan las leyes de la historia: el milagro de sobrevivir en un mundo hostil." (SOBRINO, 2013, p. 369).

Queda la pregunta de cómo se articulan los dos conceptos tratados. En principio podríamos afirmar que no se podría analizar plenamente uno de los conceptos sin relacionarlo con el otro. El pueblo se conforma fundamentalmente en torno a los pobres. Los pobres constituyen el corazón del pueblo, los que dan el sentido y el espíritu de lo que constituye lo popular y su referencialidad insoslayable. Esto puede pensarse en la línea de la construcción teológico-eclesiológica:

Sólo echando raíces en los sectores marginados y explotados; más aún, surgiendo desde ellos mismos, desde sus aspiraciones, sus intereses, sus luchas, sus categorías culturales, se forjará un pueblo de Dios que sea una iglesia del pueblo, que haga escuchar el mensaje evangélico a todos los hombres y sea signo de la liberación del Señor de la historia. (GUTIÉRREZ, 1982, p. 94).

Otra problemática de articulación está dada por las dicotomías con las que se lee la estructura social. Quizás puede decirse que para la lectura de las estructuras sociales latinoamericanas desde lo popular se presentan dos grandes esquemas dicotómicos: el clasista y el que podríamos llamar "populista". El diálogo es necesario, entre otras varias razones, porque los movimientos 
Los pobres y la praxis de lucha popular como lugar epistémico-político Félix Pablo Friggeri

populares hablan mucho más en términos de pueblo que de clase (PIXLEY; BOFF, 1986, p. 236). La potencialidad de articulación de estos conceptos analizados con la dicotomía "populista" pueblo/ oligarquía es muy grande. Articulación que no niega la articulación clasista. Aunque las diversas tendencias y autores se situarán en un potencial de articulación más acentuado con una u otra dicotomía. Expresión de esta dicotomía es el planteo "pueblo/antipueblo", que intenta remarcar fuertemente cuál es la abarcatividad del concepto pueblo y su oposición radical a la oligarquía que habita dentro del mismo país. Dri (1971) coloca temprana y claramente esta antinomia y remarca que su vigencia se da por el peronismo. Lo coloca como "un binomio de categorías indispensables para entender nuestro proceso histórico" y como "uno de los elementos que sirven al proceso de liberación nacional" (DRI, 1971, p. 19). Frantz Fanon relaciona esta dicotomía con la imposición colonial. La relación de este planteo con la dicotomía pueblo/oligarquía queda claramente expresada en este texto:

Una vez que el pueblo haya logrado no sólo reconquistar el poder, sino quebrar las estructuras de dominación capitalista, se entrará en una nueva etapa, en la que será posible el más amplio diálogo. Entre pueblo y oligarquía no puede haberlo, simplemente porque la supervivencia del pueblo exige la destrucción de la oligarquía como oligarquía. Una vez que deje de serlo no habrá límites para el diálogo.

De modo que pensamos que la antítesis pueblo-antipueblo es clave para una correcta interpretación de nuestra historia y por ende un arma indispensable para llevar adelante las luchas de liberación. No es artificial sino real. 'El espíritu oligarca se opone completamente al espíritu del pueblo. Son dos cosas totalmente distintas como el día y la noche, como el aceite y el vinagre' (Eva Perón, La historia del peronismo, SIPA, pg. 98). 'Las contradicciones entre nosotros (el pueblo) y el enemigo son antagónicas' (Mao Tse-Tung, Citas del presidente Mao, Ediciones en lenguas extranjeras, Pekin, 1966, pg. 48). (DRI, 1971, p. 25). 
Los pobres y la praxis de lucha popular como lugar epistémico-político Félix Pablo Friggeri

El mismo Scannone (2016, p. 591) que sostiene que la Teología del Pueblo -de la cual es protagonista clave- privilegia la unidad sobre el conflicto, reconoce este concepto de "antipueblo", identificándolo como la parte del pueblo que traiciona la unidad y favorece "la injusticia institucional y estructural".

\section{Praxis y sabiduría populares}

La praxis de liberación es entendida como "lugar matriz" de la teología de la liberación (ANTONCICH, 1978, p. 418), como su "punto de partida" (ALBUQUERQUE, 2016, p. 291). Retomando la importancia epistémica de las Tesis sobre Feuerbach, de Karl Marx, Gutiérrez (1982, p. 79) sostiene que:

La praxis transformadora de la historia no es el momento de la encarnación degradada de una teoría límpida y bien pensada, sino la matriz de un conocimiento auténtico y la prueba decisiva de su valor. Es el lugar en el que el ser humano recrea su mundo y se forja a sí mismo, conoce la realidad en la que se halla y se conoce a sí mismo.

En la Filosofía de la Liberación también se propone un proceso reflexivo "a partir de la comprometida praxis histórica de las masas empeñadas en el proceso liberador" (ARDILES, 1973, p. 26).

El análisis que hace Dussel sobre la praxis -especialmente desde el concepto de exterioridad- plantea que "la praxis de liberación [...] es el acto mismo por el que se traspasa el horizonte del sistema y se interna realmente en la exterioridad [...], por el que se construye el nuevo orden, una nueva formación social más justa" (DUSSEL, 1996, p. 82).

La praxis liberadora no es propiedad exclusiva del Cristianismo de Liberación, es la praxis de lucha de un pueblo, más allá de la fe que profese o no. Las comunidades cristianas participan de 
Los pobres y la praxis de lucha popular como lugar epistémico-político Félix Pablo Friggeri

una praxis que es más amplia que la suya propia (GUTIÉRREZ, 1985, p. 187). Dentro de los que protagonizan esta praxis los cristianos comprometidos con la liberación pueden brindar un aporte riquísimo desde su compromiso evangélico. Un elemento importante aquí, y no siempre recordado, es que esta praxis de lucha por la liberación no abarca solamente los acontecimientos considerados "heroicos" o de notable connotación política. Abarca, en igualdad de dignidad, la lucha cotidiana por defender la vida (TRIGO, 2011, p. 203)

El considerado "padre" de la Teología de la Liberación resalta claramente que "en primer lugar, la teología de la liberación se presenta como 'una reflexión sobre la práctica a la luz de la fe"' (GUTIÉRREZ, 2013, p. 22), es "reflexión crítica de la praxis histórica" (GUTIÉRREZ, 1985, p. 38). Es "una reflexión de fe a partir y desde dentro de la praxis de la liberación" (BOFF, 1986, p. 25).

Un problema que se tornó importante para la Teología de la Liberación fue defender y aclarar que esta praxis es teológica. Es que la crítica más dura hacia ella -sobre todo desde buena parte de las jerarquías eclesiásticas- fue poner en duda el carácter teologal de los procesos históricos de liberación (AQUINO JÚNIOR, 2016, p. 261). Así, siguiendo la argumentación de distintos autores, podemos afirmar que esta praxis es teológica:

- En cuanto que es actualización del acontecimiento pascual liberador, núcleo de la historia en la comprensión cristiana.

- En cuanto que refiere al Pueblo Crucificado que revela hoy, de la misma manera, al mismo Dios que reveló el Jesús histórico crucificado.

- Por contar con la presencia actuante (práxica) de Dios: "en las luchas de los pobres por su liberación política, económica y social sí actúa Dios" (TRIGO, 2011, p. 205).

- Porque su reflexión crítica abre al reino de Dios como don (GUTIÉRREZ, 1985, p. 41) y porque esta reflexión está 
Los pobres y la praxis de lucha popular como lugar epistémico-político Félix Pablo Friggeri

siempre "en confrontación con la palabra del Señor vivida y aceptada en la fe" (GUTIÉRREZ, 1982, p. 81).

Además, el partir desde la praxis significó una originalidad metodológica en el ámbito teológico (ALBUQUERQUE, 2016, p. 290). A la vez, implica una potenciación epistémica, ya que la praxis no es solamente un lugar de comprensión de los datos que ofrecen las fuentes del conocimiento teológico, sino el lugar en el cual y a partir del cual esos datos ofrecen lo mejor de sí (RIVAS; TAVARES, 2016, p. 224).

El paso de la praxis a la teología implica la reflexión sobre aquella, fundamentalmente la reflexión de las comunidades pobres que interpretan los signos de los tiempos y la relación de la Biblia con ellos. En ese sentido, estas comunidades conforman un magisterio que es referencia ineludible de la elaboración formal de esta teología. Es, entonces, básicamente una "ciencia de los pobres", que surge de la sabiduría de la lucha por la vida, aunque su formulación académica tenga también otras mediaciones. Así, los pobres son sujetos históricos de la praxis y, a la vez, sujetos epistemológicos de la reflexión en que debe referenciarse la Teología de la Liberación. Ya en las primeras páginas de la "obra madre" de la Teología de la Liberación -en su primer nota de pie- Gustavo Gutiérrez (1985, p. 21) recurre a Antonio Gramsci en su famoso texto en el que afirma que "todos los hombres son filósofos" para situar el origen popular de esta reflexión que se plasmará en teología.

Pero esto en la práctica no es tan simple. ${ }^{1}$ Una de las dificultades es lo que llama Trigo (2011, p. 207) “la relación ilustrada”, consistente en que "el agente solidario" es el que "tiene que enseñar y el pueblo tiene que aprender", que termina sobrecolocando una "cultura occidental" por sobre la popular, lo que termina impulsando a que "la liberación del pueblo equivalía a que el pueblo dejara de ser pueblo, perdiera su cultura popular y se occidentalizara". Podemos

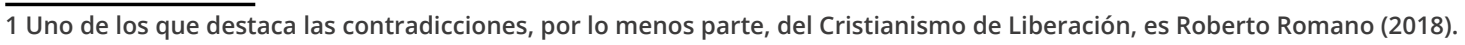


Los pobres y la praxis de lucha popular como lugar epistémico-político Félix Pablo Friggeri

decir que esto afectó tanto a animadores de comunidades (sobre todos los que no provenían de la base popular) como también a ciertos aspectos de la elaboración teológica.

También, desde los comienzos de la Filosofía de la Liberación hubo planteos resaltando esta búsqueda de un carácter popular en la producción teórica. Se exigía un discipulado en relación al pueblo y a su praxis liberadora como condición para poder aportar efectivamente a este proceso de liberación:

[...] el filósofo antes que un hombre inteligente es un hombre éticamente justo; es bueno; es discípulo. Es necesario saber situarse en el cara-a-cara, en el ethos de la liberación, para que se deje ser otro al Otro. El silenciarse de la palabra dominadora; la apertura interrogativa a la pro-vocación del pobre; el saber permanecer en el "desierto" como atento oído es ya opción ética. [...] El tema a ser pensado, la palabra reveladora a ser interpretada, le será dada en la historia del proceso concreto de la liberación misma. Esa palabra, ese tema [...] se oye en el campo cotidiano de la historia, del trabajo y aún de la batalla de la liberación. El saber-oír es el momento constitutivo del método mismo; es el momento discipular del filósofo. [...] La conversión al pensar ana-léctico o meta-físico es exposición a un pensar popular, el de los más, el de los oprimidos, el del Otro fuera del sistema; es poder aprender lo nuevo. (DUSSEL, 1973b, p. 125126).

Es cierto que en algunos momentos hubo -y de alguna forma habría que pensar que continúa y continuará- una cierta distancia y hasta cierta tensión, entre la vida de las comunidades comprometidas y la elaboración teológica. Sí, es cierto que en los principales representantes de la Teología de la Liberación se nota una conciencia y un esfuerzo para entenderla como "una obra comunitaria" que resulta de la experiencia de la praxis cristiana de liberación de las comunidades (GUTIÉRREZ, 2013, p. 23). 
Los pobres y la praxis de lucha popular como lugar epistémico-político Félix Pablo Friggeri

Aquí entra la valorización de lo experiencial-sapiencial que tiene que operar en la base de la construcción "científica" de conocimiento. Scannone (1991, p. 71) sostiene que tanto en las Ciencias Sociales como en la Teología existe "un momento experiencial anterior [...] conocido sapiencialmente" y que "ese conocimiento capta globalmente el sentido humano de la realidad social y, por ende, sus aspectos éticos".

Además, una vieja deuda, especialmente de la Teología de la Liberación, pero también en un contexto más amplio, queda planteada. El desafío de desoccidentalizar al cristianismo sobre todo en cuanto sostenedor de la "razón instrumental" que quedó al servicio del capitalismo y del imperialismo (CODINA, 2008). Las herramientas para hacerlo están presentes en la historia de los planteos liberadores, un diálogo cada vez más profundo con los movimientos indígenas es fundamental para avanzar en esa línea.

\section{Diálogos posibles}

El Cristianismo de Liberación y la Teología y la Filosofía de la Liberación, además de su vigencia práctica, temática y metodológica, tienen, también, la posibilidad de enriquecer -y ser enriquecidos- en una serie de diálogos necesarios hoy para la realidad latinoamericana. La gran mayoría de sus protagonistas actuales reconoce la necesidad de continuar un diálogo con las reflexiones que expresan la temática indígena, la afroamericana, la ecológica y la de la mujer. Éstas tuvieron una presencia relativamente discreta en los tiempos de su primer desarrollo, aunque sea importante hacer notar que en el andamiaje conceptual y metodológico de la Teología de la Liberación existe una riquísima base para profundizar este diálogo con una gran profundidad. De estos cuatro diálogos indicados, el primero, el que tiene que ver con el mundo indígena, es el que tiene una potencialidad más seminal, por su potencial descolonizador y por la maduración que esta reflexión ha podido desarrollar. 
Los pobres y la praxis de lucha popular como lugar epistémico-político Félix Pablo Friggeri

Por otro lado, ambos planteos tienen, también, que retomar su protagonismo en la reflexión sobre la construcción de los proyectos populares de liberación de nuestra región. En este protagonismo es importante la construcción de puentes tanto en la praxis como en la reflexión con otras propuestas liberadoras. ${ }^{2}$ Esto formó parte de la tarea de estos movimientos desde sus comienzos y es muy necesario actualmente.

En una crítica que realiza, Libanio (2006, p. 323) plantea que fue un error solamente proponer un solo tipo de utopía socialista y que "la Teología de la Liberación se puso a pensar la pluralidad de proyectos colectivos de una forma no centralizada ni teledirigida desde arriba". Esta pluralidad necesita diálogo y una reflexión que posibilite encuentros y articulaciones. Desde allí es importante pensar cómo el Cristianismo de Liberación y sus expresiones intelectuales pueden contribuir a la articulación práctica y reflexiva de los distintos planteos populares de liberación presentes en América Latina.

Estos planteos son múltiples y variados, pero elijo dos como ejemplos para la reflexión: el de José Carlos Mariátegui y el del Peronismo Revolucionario; y un tercero, con las propuestas del Papa Francisco por la relevancia que tienen en una revitalización del Cristianismo y de la Teología de la Liberación.

La elección del planteo mariateguiano como posibilidad de diálogo se fundamenta en que el Amauta realiza, tempranamente, un gran esfuerzo práctico y teórico para encontrar los caminos de una superación socialista del capitalismo que responda a la realidad latinoamericana, pero que, y esto es lo más importante, surja creativamente de la praxis latinoamericana, sobre todo de la ancestral indígena. En esta misma línea presenta la potencialidad revolucionaria de la espiritualidad con una fuerza con que pocos autores lo han hecho. Además, y seguramente en relación con lo anterior, estuvo claramente presente en la reflexión pionera de la

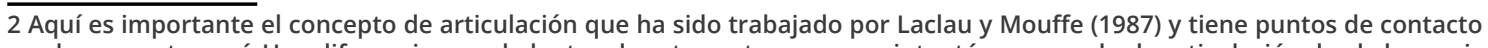
con lo expuesto aquí. Una diferencia con el planteo de estos autores es que intentó comprender la articulación desde la praxis y no como centrada en una "formación discursiva". 
Los pobres y la praxis de lucha popular como lugar epistémico-político Félix Pablo Friggeri

Teología de la Liberación, principalmente en la obra de Gustavo Gutiérrez.

Como lo destaca Löwy (2016, p. 52), Mariátegui es una referencia en el pensamiento de Gustavo Gutiérrez. Él destaca la relación que establece el pensamiento mariateguiano entre praxis y construcción del conocimiento: "No obstante, y Mariátegui lo presagió, sólo una praxis revolucionaria suficientemente vasta, rica e intensa, y con la participación de hombres provenientes de diversos horizontes, puede crear las condiciones de una teoría fecunda" (GUTIÉRREZ, 1985, p. 131).

La praxis popular es, para Mariátegui, "la realidad última e irreductible de la existencia social [...] y allí encuentra el fundamento de todo conocimiento y de toda posibilidad de transformar radicalmente la realidad social" (GERMANÁ, 1995, p. 183). Él agrega un elemento fundamental que es el carácter ancestral de esta praxis.

El Amauta desarrolla la capacidad para pensar creativamente la transformación de las estructuras sociales teniendo en cuenta el punto de vista del indio y del mestizo, y esto le es reconocido desde la Filosofía de la Liberación:

\footnotetext{
Y es que en América no nos podemos limitar cómodamente a aplicar doctrinas. Ella exige ante todo una doctrina que no solo contemple la necesidad de una transformación de las estructuras sociales y políticas o económicas, sino que también incluya la peculiar manera de ver y de sentir al hombre que alienta en el indio y en el mestizo, eso que llamé en otra oportunidad el estar. Porque pertenecen a un mundo pre-industrial, aún no enajenado en esa fácil exterioridad que brinda la vida en el burgo con sus objetos. Se mantienen aún en ese aspecto del hombre que encuentra dentro de sí el fin de su vida, su propia solución y su fuerza para modificarlo todo. Quizá Mariátegui consiguió aprehender el mismo aspecto de este problema, aunque le resultó muy difícil llevarlo adelante, en virtud del escaso instrumental que en su época había para entenderlo a fondo. (KUSCH, 1998, p. 314-315).
} 
Los pobres y la praxis de lucha popular como lugar epistémico-político Félix Pablo Friggeri

Desde su centramiento en la praxis popular y en la importancia de lo indígena en ella, Mariátegui es capaz de establecer una "búsqueda del proletariado", porque el sujeto político y epistémico revolucionario en América Latina no es algo dado, es "un problema, un interrogante más que una respuesta" y el encuentra en los pueblos indígenas "la fuente principal de la energía revolucionaria" (FLORES GALINDO, 2008, p. 371-372).

Es importante ligar esto con la mirada mariateguiana sobre la heterogeneidad estructural de nuestra región, que ha sido destacada principalmente por Aníbal Quijano, dándole también a esta mirada un potencial político y epistémico. Ese espacio cultural y político considerado como "atrasado" y pensado principalmente como una realidad a ser superada -tanto por la derecha como, muchas veces, por buena parte de la izquierda- es justamente el lugar (epistémico-político) desde el cual pueden surgir alternativas superadoras de la estructuración capitalista colonial. Es interesante relacionar esta mirada con el planteo de exterioridad que analizamos más arriba.

Así también la idea mariateguiana de "creación heroica", de "ni calco, ni copia" (MARIÁTEGUI, 2005, p. 452) puede relacionarse con la concepción dusseliana de praxis liberadora que afirma que "el otro es siempre alguien concreto en nueva posición de opresión y exterioridad, sólo el que es responsable y fiel a su novedad puede procrear e inventar lo inédito" (DUSSEL, 1996, p. 83). Esa “creación heroica" del Socialismo Indo-Americano no tiene solamente una dimensión política, sino, además, una dimensión epistémica.

La otra elección, la del Peronismo Revolucionario, para el diálogo tiene como fundamento la fuerte vigencia de un movimiento profundamente popular, que, dentro de su importante amplitud, contuvo y contiene siempre una vertiente liberadora con raíces fuertemente autóctonas. Por otro lado, este movimiento se ha convertido en paradigmático para cualquier corriente latinoamericana de lo que se da en llamar planteos nacionalpopulares o populistas en el sentido que da Ernesto Laclau al término. Finalmente, este movimiento, y, sobre todo, su vertiente 
Los pobres y la praxis de lucha popular como lugar epistémico-político Félix Pablo Friggeri

revolucionaria, fueron fundamentales en el desarrollo de la Filosofía y la Teología del Pueblo (AZCUY, 2018, p. 105); además de su vigencia, representan hoy una fuerte referencia, principalmente por ligárselo a la reflexión del Papa Francisco. Para ilustrar esta relación recurro a expresiones de dos personajes paradigmáticos de esta vertiente, las de Eva Perón, su símbolo máximo, y las de John William Cooke, su referente más importante a nivel teórico, pero también a nivel práctico.

Cooke, haciendo un comentario crítico sobre el papel de "la vanguardia revolucionaria", esboza por dónde va la construcción teórica: la relación con la praxis popular enriquecida por el pensamiento crítico y cómo su valor revolucionario se comprueba en la praxis:

[...] la vanguardia revolucionaria no es una minoría autodesignada en mérito a la admiración que a sí mismo se profesa, sino el cumplimiento de una función que hay que revalidar constantemente mediante la comprensión teórica de una realidad fluyente que escapa a toda sabiduría inmóvil centelleante de verdades definitivas. Con eso estamos afirmando, en primer lugar, que ese conocimiento no es exterior a la práctica de las masas, sino la experiencia directa de esa lucha enriquecida por el pensamiento crítico. Y, además, que tal conocimiento solo adquiere valor revolucionario en cuanto se 'socializa' al ser incorporado por las masas a su acción, pues ellas son las actoras y también las destinatarias de la revolución. (COOKE, 2011, p. 21-22).

Eva Perón comprende su trabajo de liderazgo político como una encarnación en el pueblo:

Es lindo vivir con el pueblo. Sentirlo de cerca ... Sufrir con sus dolores y gozar con la simple alegría de su corazón. Pero nada de todo eso se puede si previamente no se ha decidido definitivamente 'encarnarse' en el pueblo [...] hacerse una sola 
Los pobres y la praxis de lucha popular como lugar epistémico-político Félix Pablo Friggeri

carne con él para que todo dolor y toda tristeza y angustia y toda alegría del pueblo sea lo mismo que si fuese nuestra [...] Eso es lo que yo hice, poco a poco en mi vida [...] Por eso el pueblo me alegra y me duele. Me alegra cuando lo veo feliz [...] y cuando yo puedo añadir un poco de mi vida a su felicidad. $Y$ me duele cuando sufre [...]. (DUARTE DE PERÓN, 2016).

Un pueblo humillado y despreciado al que ella pertenece y al cual, a pesar de su relevante posición, sigue perteneciendo y al mismo tiempo marcando la dicotomía pobres/ricos en su comprensión de la sociedad:

Yo declaro que pertenezco ineludiblemente y para siempre a la 'ignominiosa raza de los pueblos'. De mi no se dirá jamás que traicioné a mi pueblo, mareada por las alturas del poder y de la gloria. Eso lo saben todos los pobres y todos los ricos de mi tierra. Por eso me quieren los descamisados y los otros me odian y me calumnian. Nadie niega en mi Patria que para bien o para mal, yo no me dejé arrancar el alma que traje de la calle. (DUARTE DE PERÓN, 2016).

Pero me animo a decir que Eva tiene elementos para ser considerada una precursora de lo que se llamará Cristianismo de Liberación, como lo podemos ver en estos textos:

Yo soy y me siento cristiana. Soy católica, pero no comprendo que la religión de Cristo sea compatible con la oligarquía y el privilegio. Esto no lo entenderé jamás. Como no lo entiende el pueblo. (DUARTE DE PERÓN, 2016).

[...] lo quiero a Cristo mucho más de lo ud. cree: yo lo quiero en los descamisados. ¿Acaso no dijo Él que estaría en los pobres, en los enfermos, en los que tuviesen hambre y en los que tuviesen sed? (DUARTE DE PERÓN, 1951, p. 218). 
Los pobres y la praxis de lucha popular como lugar epistémico-político Félix Pablo Friggeri

Es muy interesante, en este sentido, su comprensión de la Navidad:

La nochebuena es de los pobres, de los humildes, de los descamisados desde que Cristo, despreciado por los ricos que le cerraron todas las puertas, fue a nacer en un establo [...] y ¿acaso los ángeles no llamaron a los pastores, a los hombres más humildes y pobres de Belén [...] y únicamente a ellos les comunicaron la buena nueva que venía a alegrar al mundo? Únicamente a los pastores, a los humildes, a los pobres les fue anunciada la 'paz a los hombres de buena voluntad ...' (DUARTE DE PERÓN, 1951, p. 217).

Sobre el sentido que tiene "la religión", sostiene:

La religión debe levantar la cabeza de los hombres. Yo admiro a la religión que puede hacerle decir a un humilde descamisado frente a un emperador: 'iYo soy lo mismo que Usted, hijo de Dios!' La religión volverá a tener su prestigio entre los pueblos si sus predicadores la enseñan así: como fuerza de rebeldía y de igualdad, no como instrumento de opresión. Predicar la resignación es predicar la esclavitud. Es necesario, en cambio, predicar la libertad y la justicia. ¡Es el amor el único camino por el que la religión podrá llegar a ver el día de los pueblos!

[...] Yo no creo, como Lenin, que la religión sea el opio de los pueblos. La religión debe ser, en cambio, la liberación de los pueblos; porque cuando el hombre se enfrenta con Dios alcanza las alturas de su extraordinaria dignidad. [...] Dios existe y por Él somos dignos, y por Él todos somos iguales, y ante Él nadie tiene privilegios sobre nadie. ¡Todos somos iguales! Yo no comprendo entonces por qué, en nombre de la religión y en nombre de Dios, puede predicarse la resignación frente a la injusticia. $\mathrm{Ni}$ por qué no puede en cambio reclamarse, en nombre de Dios y en nombre de la religión, esos supremos derechos de todos a la justicia y a la libertad. La religión no ha de ser jamás instrumento de opresión para los pueblos. Tiene que ser bandera de rebeldía. 
Los pobres y la praxis de lucha popular como lugar epistémico-político

Félix Pablo Friggeri

[...] Yo me rebelo contra las 'religiones' que hacen agachar la frente de los hombres y el alma de los pueblos. Eso no puede ser religión. (DUARTE DE PERÓN, 2016).

Y es, justamente, la "encarnación en el pueblo" la actitud que evidencia una verdadera fe:

\begin{abstract}
Yo vivo con mi corazón pegado al corazón de mi pueblo y conozco por esto todos sus latidos. Yo sé como siente, como piensa y como sufre. [...] Mi mensaje está destinado a despertar el alma de los pueblos de su modorra frente a las infinitas formas de opresión, y una de esas formas es la que utiliza el profundo sentimiento religioso de los pueblos como instrumento de esclavitud. [...] La religión es para el hombre y no el hombre para la religión, y por eso la religión ha de ser profundamente humana, profundamente popular. Y para que la religión sea así, profundamente popular; debe volver a ser como antes. Ha de volver a hablar en el lenguaje del corazón que es el lenguaje del pueblo [...]. (DUARTE DE PERÓN, 2016).
\end{abstract}

Entiendo que el sentido que da a su vida entera es la praxis de liberación, cuando afirma que tiene: "un deseo irrefrenable de quemar mi vida para alumbrar el camino de la liberación popular" (DUARTE DE PERÓN, 2016).

Un tercer espacio de diálogo que se abre es, llamativamente, con el pensamiento oficial de la Iglesia Católica desde la asunción del Cardenal Jorge Bergoglio como Papa Francisco.

En esta relación del Cristianismo de Liberación y de la Teología ligada a él con El Vaticano no hay que ignorar que hubo un trabajo concreto de sectores poderosos de la Iglesia para destruir la inmensa y fecunda experiencia del Cristianismo de Liberación, especialmente en cuanto a la vitalidad de las Comunidades Eclesiales de Base, y también de la Teología de la Liberación (COMBLIN, 2007, p. 237). Codina (2016, p. 235) habla del "duro invierno eclesial de los años de Juan Pablo II y Benedicto XVI, 
Los pobres y la praxis de lucha popular como lugar epistémico-político Félix Pablo Friggeri

con fuertes críticas a la TdL". Una de las herramientas utilizadas en esta ofensiva fue el nombramiento de obispos contrarios al Cristianismo de Liberación, especialmente en los lugares donde más vitalidad tenía (LÖWY, 2016, p. 94). Por eso puede hablarse de una "hostilidad sistemática del Vaticano", por lo menos durante un buen tiempo (LOWY, 2016, p. 200).

Si tomamos como ejemplo la figura del obispo Óscar Romero, alguien muy cercano a esa figura recordaba que "oligarquías, militares, gobiernos y también algunos poderes eclesiásticos han querido silenciar y enterrar a Monseñor" (SOBRINO, 2005, p. 210) y reclamaba que "la Iglesia vaticana, junto a otros pecados, pidiese también perdón por el trato que, en vida, dio a Monseñor Romero y a varios otros obispos, sacerdotes, teólogos, laicos y laicas" (SOBRINO, 2005, p. 219).

La elección del obispo Bergoglio, considerado como alguien contrario al Cristianismo de Liberación, parecía continuar la predominancia de una relación negativa con elVaticano. Sin embargo, tanto en una serie de hechos como en la doctrina producida por el Papa argentino se presentaron gestos y posibilidades de un diálogo que comenzó a gestarse.

Hay algunas cercanías temáticas que pueden ser destacadas.

La necesidad de aprender de los pobres es remarcada en Evangelii Gaudium 198: "ellos tienen mucho que enseñarnos" y de "recoger la misteriosa sabiduría que Dios quiere comunicarnos a través de ellos". Unido a esto, la revalorización del concepto de "sensus fidei" o "sentido de la fe" (SCANNONE, 2016, p. 595), da al pueblo en cuanto sujeto una importante dimensión epistémica como un criterio de lectura cristiana de la realidad y de la fe que desborda los límites de una lectura jerárquica de las mismas (GALLI, 2018, p. 96).

Hay quienes opinan que Francisco ha retomado algunas de las "intuiciones fundacionales" de la Teología de la Liberación al plantear en su ministerio pastoral "la impostergable cercanía de la Iglesia con los excluidosy 'descartables'". (MENDOZA-ÁLVAREZ, 2016, 
Los pobres y la praxis de lucha popular como lugar epistémico-político Félix Pablo Friggeri

p. 270). Este tipo de expresiones y gestos lleva a afirmar a algunos exponentes de la Teología de la Liberación que "actualmente se experimenta una nueva primavera eclesial inaugurada por Francisco con la propuesta de una Iglesia pobre y para los pobres" (CODINA, 2016, p. 236).

De todas formas, las cercanías históricas del Papa Francisco con este movimiento vienen sobre todo por la Teología del Pueblo, con la que tuvo fuertes contactos desde sus tiempos de formación (LÖWY, 2016, p. 220; MENDOZA-ÁLVARES, 2016, p. 283; SCANNONE, 2016, p. 586). A esta vertiente teológica atribuyen el planteo de la "pirámide invertida" o de la "sinodalidad del Pueblo de Dios", que implican entender la configuración eclesial con la cima por debajo de la base y su dinámica como un caminar y reflexionar juntos (GALLI, 2018, p. 93-96). Para Scannone (2016, p. 592), Francisco la "vuelve a hacer fructificar y la ofrece de nuevo a la Iglesia universal".

La gran vinculación pasa por la opción por los pobres y, en este punto, hay quienes interpretan que hay una profundidad notable en el Papa Francisco que lo vincula a toda la teología latinoamericana (GALLI, 2018, p. 99).

Institucionalmente, uno de los signos más fuertes ha sido la canonización de Oscar Romero. Y en Argentina, especialmente, la consolidación del camino de beatificación de los mártires riojanos: el obispo Enrique Angelelli, el laico Wenceslao Pedernera y los curas Carlos Murias y Gabriel Longueville, todos asesinados por la dictadura militar en 1976.

Pero también ha sido de "gran valor simbólico" para la teología latinoamericana la cercanía expresada por el Cardenal Gerhard Müller, a cargo de la anteriormente agresiva Congregación de la Doctrina de la $\mathrm{Fe}$ y y su reconocimiento del valor de la Teología de la Liberación, además del hecho de haber publicado junto a Gustavo Gutiérrez en 2013 (CODINA, 2016, p. 230).

Hay, también, visiones más críticas, que expresan que las contradicciones en las posturas que tuvo como obispo en la Argentina y las que tiene ahora en el Papado tienen que ver con 
Los pobres y la praxis de lucha popular como lugar epistémico-político Félix Pablo Friggeri

una visión de poder y de búsqueda de reconstrucción del poder eclesial desde América Latina y sus movimientos populares. Esta actitud redituaría en un importante apoyo para estos movimientos, aunque también planteando algunos límites a ellos (DRI, 2015).

Quizás la gran duda es si existe la posibilidad de una revitalización del Cristianismo de Liberación, cuya expresión eclesial más emblemática son las Comunidades Eclesiales de Base. La represión que recibieron las CEBs fue aplastante y en muchos sectores eclesiales sigue existiendo. Hay expresiones claras de aperturay ciertasintonía con muchos de los contenidos enarbolados por la Teología de la Liberación, pero no hay claridad en una acción decidida a promover el resurgimiento de las Comunidades dentro de la praxis eclesial. Así, parece más probable que se revitalicen ciertas expresiones de la Teología de la Liberación, pero parece bastante más distante la revitalización de las Comunidades que son parte fundamental de su lugar epistémico. De esta forma, la mirada al futuro es compleja.

\section{Consideraciones finales}

La reflexión sobre el concepto de pobre tiene algunas potencialidades de gran actualidad. Una de ellas es enriquecer el tratamiento del tema de la pobreza y del "combate" a ella en el ámbito de la reflexión que acompaña a los organismos internacionales y a las políticas públicas de nuestros países.

Tanto los conceptos de pobre, de pueblo, de praxis de liberación y de sabiduría popular pueden ser elementos claves en la discusión sobre el tipo de sujeto político y epistémico que puede protagonizar tanto una praxis como una reflexión sobre ella que protagonice un camino liberador para nuestra región latinoamericana. Dicho desde la discusión ligada al marxismo, es la pregunta por la ampliación del proletariado y su identificación en América Latina. 
Los pobres y la praxis de lucha popular como lugar epistémico-político Félix Pablo Friggeri

En cuanto sujeto epistémico, esto se relaciona con la construcción y/o reconocimiento de una "ciencia popular" y con la incorporación de lo popular como condición indispensable para la valoración de la "excelencia" en el trabajo científico. El valor de la sapiencialidad en relación con lo científico es otro elemento de discusión que vale la pena trabajar. Aquí el concepto de "discipulado" del mundo intelectual en relación al popular es clave y puede operar como guía de implementación en los actuales lugares de "producción de conocimiento".

Las relaciones entre los conceptos de pueblo, clase y nación son otro aspecto de múltiples repercusiones en la discusión de las Ciencias Sociales. Para las relaciones entre Pueblo y Nación sería muy enriquecedor un diálogo con todo lo que se ha venido reflexionando sobre el tema en torno a los movimientos indígenas en América Latina y, muy especialmente, en los procesos ligados al Nuevo Constitucionalismo Latinoamericano, representado en forma destacada en las constituciones ecuatoriana y boliviana. En cuanto a la problemática de clases, entiendo que tanto la Teología como la Filosofía de la Liberación pueden hacer un gran aporte para una revalorización del análisis de clase en forma situada e historizada en nuestra región. Aquí es clave también el diálogo entre las dicotomías clasista y populista que se planteó más arriba.

El hecho de que tanto la Teología como la Filosofía de la Liberación hayan planteado siempre una doble dimensión política y epistémica en sus trabajos colabora con el enorme desafío de las Ciencias Sociales, y particularmente para aquellos que la trabajan desde un compromiso popular, de ser capaces de proponer planteos revolucionarios desde una creatividad y originalidad -mariateguianamente dicho esto- propiamente latinoamericanas. 


\section{Referencias}

ALBUQUERQUE, Francisco das Chagas de. Teologia da Libertação na pós-modernidade: contribuição à humanização. Perspectivas Teológicas, Belo Horizonte, v. 48, n. 2, p. 289-316, maio/ago. 2016.

ANTONCICH, Ricardo. Hermenéutica de los documentos sociales del Magisterio y Praxis de la Liberación. Perspectiva Teológica, v. 10, n. 22, p. 403-434, 1978.

AQUINO JÚNIOR, Francisco de. Questões fundamentais de Teologia da Libertação. Perspectivas Teológicas, Belo Horizonte, v. 48, n. 2, p. 245-268, mai/ago. 2016.

ARDILES, Osvaldo. Bases para una de-strucción de la Historia de la Filosofía en la América Indo-lbérica. Prolegómenos para una Filosofía de la Liberación. In: ARDILES, Osvaldo et al. Hacia una Filosofía de la Liberación Latinoamericana. Buenos Aires: Bonum, 1973. p. 7-26.

AZCUY, Virginia R. Lucio Gera, un teólogo de Medellín. Revista Teología, Tomo LV, n. 126, p. 103-131, septiembre 2018.

BOFF, Leonardo. Iglesia: carisma y poder. Ensayos de eclesiología militante. 2. ed. Santander: Sal Terrae, 1984.

BOFF, Leonardo Teología desde el lugar del pobre. Santander: Sal Terrae, 1986.

CASALLA, Mario C. Filosofía y cultura nacional en la situación latinoamericana contemporánea. In: ARDILES, Osvaldo et al. Hacia una Filosofía de la Liberación Latinoamericana. Buenos Aires: Bonum, 1973. p. 38-52.

CODINA, Víctor. Desoccidentalizar el cristianismo. Perspectiva Teológica, n. 40, p. 9-23, 2008. 
Los pobres y la praxis de lucha popular como lugar epistémico-político

CODINA, Víctor. Nuevos desafíos de la Teología de la Liberación. Perspectivas Teológicas, Belo Horizonte, v. 48, n. 2, p. 229-243, maio/ago. 2016.

COMBLIN, José. Mirando hacia el futuro. Selecciones de Teología, v. 46, n. 183, p. 224-240, 2007.

COOKE, John William. Obras completas. Tomo V. Buenos Aires: Colihue, 2011.

DRI, Rubén. Bergoglio-Francisco y la Patria Grande. Revista Política Latinoamericana, Buenos Aires, n. 1, julio-diciembre 2015.

DRI, Rubén. Pueblo y antipueblo. Revista Envido, n. 3, p. 19-25, 1971.

DUARTE DE PERÓN, María Eva. La razón de mi vida. Buenos Aires: Peuser, 1951.

DUARTE DE PERÓN, María Eva. Mi mensaje. El ortiba. Disponible en: http://www.elortiba.org/mimen.html. Consultado el: 29-10-2016.

DUSSEL, Enrique. Caminos de la liberación latinoamericana II. Teología de la Liberación. Ética. Buenos Aires: Latinoamericana, $1973 a$.

DUSSEL, Enrique. El método analéctico y la filosofía latinoamericana. In: ARDILES, Osvaldo et al. Hacia una Filosofía de la Liberación Latinoamericana. Buenos Aires: Bonum, 1973b. p. 118-137.

DUSSEL, Enrique. Ética comunitaria. Florida, Argentina: Paulinas, 1986.

DUSSEL, Enrique. Filosofía de la liberación. Bogotá: Nueva América, 1996.

DUSSEL, Enrique. Historia de la Iglesia en América Latina. Medio milenio de coloniaje y liberación (1492-1992). 6. ed. Madrid: Mundo Negro, 1992. 
Los pobres y la praxis de lucha popular como lugar epistémico-político Félix Pablo Friggeri

ELLACURÍA, Ignacio. El pueblo crucificado. In: ELLACURÍA, Ignacio; SOBRINO, J., Mysterium Liberationis. Conceptos fundamentales de la teología de la liberación. Tomo II. Madrid: Trotta, 1990b. p. 189-216.

ELLACURÍA, Ignacio. El pueblo crucificado, ensayo de soteriología histórica. Revista Latinoamericana de Teología, San Salvador: Centro de Reflexión Teológica, v. 6, n. 18, p. 305-333, sep./dic. 1989.

ELLACURÍA, Ignacio. El pueblo crucificado signo de los tiempos. Selecciones de Teología, v. 29, n. 116, 1990c.

ELLACURÍA, Ignacio. La Iglesia de los pobres, sacramento histórico de liberación. In: ELLACURÍA, Ignacio; SOBRINO, J. Mysterium Liberationis. Conceptos fundamentales de la teología de la liberación. Tomo II. Madrid: Trotta, 1990a. p. 127-153.

ELLACURÍA, Ignacio. Los pobres, lugar teológico en América Latina. Misión abierta, n. 4-5, p. 225-240, 1981.

FLORES GALINDO, Alberto. Obras completas. Tomo V. Lima: Sur, 2008.

GALLI, Carlos María. Revolución de la ternura y reforma de la Iglesia. Medellín, Bogotá, v. XLV, n. 170, p. 73-108, enero-abril, 2018.

GERMANÁ, César. El “Socialismo Indo-americano" de José Carlos Mariátegui: Proyecto de reconstitución del sentido histórico de la sociedad peruana. Lima: Amauta, 1995.

GUTIÉRREZ, Gustavo. La fuerza histórica de los pobres. Salamanca: Sígueme, 1982.

GUTIÉRREZ, Gustavo. La Teología latinoamericana y caribeña. Trayectoria y perspectivas. Páginas, n. 38, p. 14-29, 2013.

GUTIÉRREZ, Gustavo. Teología de la Liberación. Perspectivas. 11. ed. Salamanca: Sígueme, 1985. 
Los pobres y la praxis de lucha popular como lugar epistémico-político Félix Pablo Friggeri

$\mathrm{KUSCH}$, Rodolfo. El pensamiento indígena y popular en

América. Buenos Aires: Hachette, 1977.

$\mathrm{KUSCH}$, Rodolfo. Esbozo de una Antropología Filosófica

Americana. San Antonio de Padua: Castañeda, 1978.

$\mathrm{KUSCH}$, Rodolfo. Obras completas. Tomo II. Rosario: Fundación Ross, 1998.

LIBANIO, Joao Batista. Teología de la Liberación. Nuevas figuras. Selecciones de Teología, v. 45, n. 180, p. 323-330, 2006.

LÖWY, Michael. O que é Cristianismo da Libertação? Religião e política na América Latina. São Paulo: Expressão Popular, 2016.

MARIÁTEGUI, José Carlos. Invitación a la vida heroica. Lima: Fondo Editorial del Congreso del Perú, 2005.

MENDOZA-ÁLVAREZ, Carlos. La Teología de la Liberación en contexto posmoderno en América Latina y el Caribe. Perspectivas Teológicas, Belo Horizonte, v. 48, n. 2, p. 269-288, maio/ago. 2016.

MORA RODRÍGUEZ, Luis Adrián. El pobre y la pobreza como exterioridad: la construcción de una alternativa política utópica para América Latina desde la filosofía de Enrique Dussel. Buenos Aires: CLACSO, 2017.

MORENO, Juan Ramón. Evangelización. In: ELLACURÍA, Ignacio; SOBRINO, J., Mysterium Liberationis. Conceptos fundamentales de la teología de la liberación. Tomo II. Madrid: Trotta, 1990. p. 155-174.

PIXLEY, Jorge; BOFF, Clodovis. Opción por los pobres. Florida, Argentina: Paulinas, 1986.

RIVAS, Eugênio; TAVARES, Sinivaldo S. A perene e irrenunciável tarefa de uma teologia libertadora. Perspectivas Teológicas, Belo Horizonte, v. 48, n. 2, p. 223-228, maio/ago. 2016.

ROMANO, Roberto. Memórias da esquerda, católica e não católica. Contra a Razão de Estado, 9 de febrero de 2018. Disponible 
Los pobres y la praxis de lucha popular como lugar epistémico-político Félix Pablo Friggeri

en: https://forumdiderot.blogspot.com/2018/02/roberto-romano-memorias-da-esquerda.html. Consultado el: 2/10/2019.

SCANNONE, Juan Carlos. Reflexiones epistemológicas acerca de las tres dimensiones (histórica, teórica y práctica) de la Doctrina Social de la Iglesia. In: HÜNERMANN, P.; SCANNONE, Juan Carlos (Comp.). América Latina y la doctrina social de la Iglesia. Diálogo latinoamericano-alemán. Reflexiones metodológicas. Buenos Aires: Paulinas, 1991. p. 55-86.

SCANNONE, Juan Carlos. Vientos nuevos del Sud: La teología argentina del pueblo y el Papa Francisco. Revista Pistis \& Praxis. Teología y Pastoral, Curitiba, v. 8, n. 3, p. 585-611, set./dez. 2016. SOBRINO, Jon. La santidad primordial. Concilium, n. 351, p. 365377, 2013.

SOBRINO, Jon. Monseñor Romero: exigencia, juicio y Buena Noticia en el XX aniversario de su martirio. Selecciones de Teología, v. 44, n. 175, p. 209-222, 2005.

TRIGO, Pedro. La acción de Dios en la historia según la teología latinoamericana. Selecciones de Teología, v. 50, n. 199, p. 193213, 2011.

VERDUGO, Fernando. Relectura de Medellín: desafíos actuales para la Teología. Teología y Vida, v. 59, n. 1, p. 111-127, 2018. 